\title{
CATOLICISMO E DESENVOLVIMENTO VARGUISTA: NEXOS DO APOIO DA ARQUIDIOCESE DE PORTO ALEGRE AO ESTADO BRASILEIRO NO PERÍODO PÓS-1930
}

Artur César Isaia*

\section{INTRODUÇÃO}

O período pós-1930 caracterizou-se pela intensificação das transformaçôes socioeconômicas e culturais, que há algum tempo já mostravam-se operantes no Brasil. ( $)$ aprofundamento do capitalismo e o surgimento de novos atores sociais impunham a necessidade de ruptura com padrōes nos quais secularmente assentava-se a vida nacional e o arcabouço institucional do Estado. Por outro lado, a manutenção de estruturas denunciadoras das limitaçōes (e da própria racionalidade) das transformaçōes apresentadas, revelava uma ampla maioria da populaçāo ainda imersa em um universo simetricamente oposto à afirmação da modernidade. Esta adquire no Brasil do século XX a força de uma miragem, transformada em meta emblemática pelo Estado pós-1930, antecipando, em um país periférico, o plano onírico à realidade social. ${ }^{1}$

Este artigo pretende perseguir a reação do posicionamento oficial da Arquidiocese de Porto Alegre frente a um Estado que se apresentava à sociedade civil como portador de um projeto desenvolvimentista, capaz.

\footnotetext{
* Curso de Pós-Graduação em História. FHC/PUCRS. Porto Alegre-RS.
} 
de endossar a sede do novo que freqüentava há algum tempo as inquietaçôes das vanguardas culturais e empresariais do país.

\section{A RECONSTRUÇÃO NACIONAL DA PERCEPÇÃO ARQUIDIOCESANA}

A leitura dos pronunciamentos oficiais da Arquidiocese de Porto Alegre evidencia uma proposta de sociedade, que alicerçada $\mathrm{cm}$ princípios constantes da idéia de recristianização, apontava para a edificaçāo da "reconstrução nacional".

() ano de 1930 era visto como um corte histórico, capaz de inaugurar um tempo novo para o Brasil. Esta nova etapa marcava-se pela construção de um Estado harmonizado com o caráter nacional, que reclamava a presença do catolicismo como força sobrenatural de preservaçāo de sua identidade.

A importância que a Igreja demonstrava e que a fazia respeitada pelo poder secular era vista como o ressurgir de uma força atávica, reveladora de um destino providencial para o Brasil. No momento em que a realidade mundial ostentava os efeitos de uma corrosão no sistema de crenças e valores que sustentavam a ordem social e política, o Brasil, orientado pelo magistério da Igreja, poderia mostrar ao mundo um protótipo de convivência humana, desde que resguardasse incólume sua tradição cristã.

À medida em que o Estado brasileiro "conciliava-se" novamente com as raízes cristãs da nacionalidade, passava a ostentar a um mundo laicizado e paganizado, o papel de reedificador da cristandade. $\mathrm{O}$ mesmo Brasil que se "reconciliava" com sua história após o triste espetáculo de uma república liberal e agnóstica, estava predestinado a um papel apostólico e civilizador:

“() Brasil deve ser a coluna inabalável da civilização cristã. É este o desejo de todo os bons brasileiros. E quando as outras naçōes tatearem nas trevas das dúvidas e dos erros, a Terra de Santa Cruz levantará bem alto o luminoso facho da verdade, do direito, da justiça e da genuína fraternidade, para mostrar aos povos o caminho que devem seguir, a fim de se tornarem felizes e prósperos. 
() Brasil não favorecerá a decadência da civilização, será o seu baluarte inexpugnável, construído sobre ofundamento das leis de Deus e os ensinamentos de Cristo". 2 .

Com o "eclipse da França e o colapso da Itália" assentuava-se o novo papel a ser desempenhado pelo Brasil na ordem internacional da década de 1940, ou scja, o de empunhar "a flâmula da latinidade, imobilizada na Europa entre os escombros da destruiçâo". 4

Quando o arcebispo refere-se ao "papel destinado pela Providência" ao Brasil na reconstrução de um mundo, está endossando uma postura em que se privilegia, nesta reedificação, o papel protagonista do Estado. Este, sob influxo salutar das "gloriosas forças militares e das nobres classes conservadoras", 5 abertas à influência da Igreja, conduziria a sociedade a um padrão de convivência humana alicerçado na vontade de Deus.

A Igreja, através da possibilidade de efetivar mediações junto aos setores dominantes, ofereceria ao Estado as coordenadas capazes de moldar a sociedade brasileira, instaurando-se uma ordem distinta, tanto na criada pela "desenfreada libertinagem individual" do liberalismo, quanto da "grotescamente estatal e desumana" do comunismo."

Ligada a um passado histórico que a identificava com as raízes da nacionalidade, a Igreja oferecia ao Estado Brasilciro a possibilidade de lançar-se, não só à recristianização de sua sociedade, mas de impulsionar na mesma direção o mundo todo.

Ao mesmo tempo em que o estado brasileiro era alçado a uma tarefa apostólica frente a um mundo combalido pela guerra, crescia, por isso mesmo, a importância da Igreja, como guardiã da verdade c detentora da doutrina salvadora a ser implementada.

A nova ordem a ser criada, logicamente que seria edificada segundo os parâmetros da cristandade, abandonados com a laicização que acompanhou o fim do período medieval. Nessa época, a vida individual e as instituiçōes sociais estavam organicamente vinculadas à aceitação das normas da Igreja, penetrando as conseqüências disso em todos os espaços da vida em sociedade. Sendo assim, colocava-se em destaque no discurso de D. João Becker a necessidade de imprimir novamente uma unidade moral, capaz de avaliar uma convivência social permeada pela ética cristã. Dessa forma, era necessário unir novamente ao atos humanos e a vida social à moralidade ditada pelos imperativos religiosos. ${ }^{7} \mathrm{O}$ modelo de 
edificação da nova ordem social deveria ser buscado na cristandade medieval. ${ }^{8}$

"É concepção nitidamente cristã que o homem possui determinados direitos naturais que the outorgam uma personalidade intangível, os quais, sem dúvida, o Estado é obrigado a respeitar e garantir.

$\mathrm{Na}$ Idade Média essa idéia florescia e se enraizou nas escolas filosóficas e nas discussões científicas. Saindo desde logo da esfera especulativa, tomou as formas concretas de instituiçôes positivas de reconhecida eficácia e influxo na vida dos povos". ${ }^{9}$

A argumentação do arcebispo acerca da reconstrução social buscava fundamentação, sobretudo, no pensamento de Sâo Tomás, para quem a problemática da moralidade individual e social colocava-se como prioritária para a preservaçāo do "corpo social". Em São Tomás, o destino individual e social não sāo diferentes. Sendo o beatitude o lim supremo da vida do homem, a sociedade devia estruturar-se para permitir que os indivíduos chegassem a gozá-la, de forma perfeita, na vida eterna.

A beatitude a que o homem está destinado concretizava-se já, de maneira imperfeita, nesta vida. Essa beatitude consistia na prática da virtude. É exatamente neste ponto que a questão de reordenação social aparecia como imperativo de salvação individual e social. Para a prática da virtude era necessário, segundo São Tomás, que o homem não carecesse do indispensável para a vida digna. Sendo assim, a miséria colocava-se como sintoma de uma ordenação social fora dos parâmetros cristāos e como empecilho à concretização do destino sobrenatural do homem e da sociedade. ${ }^{10}$

A existência de uma ordem social corporativa, na qual o homem tivesse uma vida digna, nāo aviltada pelas condições desumanas que o afastasse de suas obrigações espirituais e da prática da virtude, impunha-se como o fundamento de uma convivência humana escudada nos ensinamentos da Igreja:

"A beatitude desta vida consiste na prática da virtude; porém o exercício da virtude requer a cooperação do corpo e de um certo conjunto de bens materiais. Sem dúvida, observa o Doutor Angélico, estas duas necessidades do homem, a prática da virtude e a posse dos bens terrestres, podem encontrar-se na família; mas somente se realizam nela duma 
maneira restrit a c incompleta; na sociedade civil encontram-se duma mancira geral e perfeita"."

\section{ESTADO, MODERNIZAÇÃO E O PROJETO ARQUIDIOCESANO}

A vida moderna, alicerçada em uma cultura laica e em instituições baseadas no individualismo liberal, nāo oferecia condiçôes para que a virtude humana florescesse. Ao contrário, ao invés de possibilitar ao homem uma vida melhor, o progresso" do mundo contemporâneo, na verdade, impunha uma existência rebaixada, muito distante de possibilitar ao homem a concretizaçāo de seu destino transcendental. Em sua vigésima sétima Carta Pastoral, publicada pouco tempo antes da decretaçāo do Estado Novo, o arcebispo traça um sombrio quadro da sociedade moderna, não vendo outra alternativa para o caos que se perpetuava, fora de uma conversão total aos princípios do catolicismo. ${ }^{12}$

O papel da Igreja Católica na reconstrução do mundo coloca-se como um imperativo, sem o qual qualquer tentativa de enfrentamento dos problemas sociais seria ineficaz e falso. À época que o Brasil e o mundo estavam vivendo, a Igreja colocava seu magistério como a única alternativa eficaz de fugir-se ao espectro da revolução social c da tirania. Por isso escrevia o arcebispo:

"Já não defendemos nossa fé, mas dela nos ufanamos; já não mendigamos consideraçōes para a Igreja, mas, unicamente, perguntamos, se querem aproveitar os seus ensinamentos e preceitos, ou se querem parecer, visto que, se a sociedade nāo quer salvar-se por meio da Igreja, não haverá, possibilidade de salvação". ${ }^{13}$

A conversão da sociedade contemporânea aos ensinamentos da Igreja impunha-se de maneira total, sem tergiversar em nenhum ponto do seu magistério:

"Há somente um meio de salvação e este consiste em voltar à observância dos preceitos do cristianismo, em voltar à Igreja.

Faça nossa sociedade esse ensaio e o resultado será magnífico. Ela nāo se arrependerá de ter assim procedido, mas lamentará nāo haver já feito isto há mais tempo. 
Porém, esta volta deve processar-se em todos os domínios da cultura e da civilizaçâo. Ou tudo ou nada; ou tudo ou todos os melhores esforços serão inúteis. Pois, os princípios morais e religiosos são o sangue que circula em todas as veias ou departamentos da sociedade. Se estes princípios, que são os mandamentos de Deus, não são renovados nos coraçōes, em cada tentativa de melhora, nenhuma reforma obterá resultados positivos". ${ }^{14}$

Essa "reconquista do Brasil para Cristo" deveria, então, atingir a toda vida nacional. Atingiria, desde as instituições socioeconômicas, cristianizadas pela adoção dos princípios corporativos, até as bases em que se assentava o Estado, que resguardando as prerrogativas católicas, tornaria a família incólume às influências desagregadoras.

Um Estado capaz de garantir a presença ativa do catolicismo como força legitimante e enquadradora da opinião pública, através de sua aliança com a Igreja, teria que assentar-se sobre uma base material favorável a esse fim. É justamente nesse ponto que se encontra a separação entre o esforço modernizador capitaneado pelo Estado e o ideal social proposto pela Arquidiciocese de Porto Alegre.

D. João Becker inclinava-se pela preservação de uma base social de cunho agrário, amparada na família numerosa, temente a Deus e apta para fornecer vocaçōes abundantes à Igreja. Ou seja, o arcebispo tendia para a defesa da perpetuação do panorama socioeconômico visível na zona colonial rio-grandense, como ideal para a manutenção de um Brasil católico.

Em 1932, por exemplo, o jornal da Arquidiocese, comentando a necessidade da arregimentação dos católicos para as futuras eleições, afirma:

"Se persistir a indiferença eleitoral da grande massa do povo, precisamente mais sâo, ordeiro e trabalhador do interior, as minorias turbulentas dos socialistas e comunistas, que se estāo organizando, poderão de futuro conquistar preponderância nas assembléias legislativas e imprimir à nossa legislação uma direção e feição de suas funestas idéias". ${ }^{15}$

É o elogio à população do interior, que se mantinha fiel à Igreja, ainda incólume à influência das "minorias turbulentas", que nas grandes cidades entregavam-se às reivindicações sociais, fora do controle do catolicismo. A Arquidiocese salientava as vantagens morais, econômicas 
e físicas da vida rural e interiorana, mais propensa a permitir famílias numerosas, "as mais queridas por Deus". ${ }^{16}$ As grandes famílias, eram vistas como as únicas que “... dão Santos aos céus e dão auxiliares à Igreja para a salvação das almas". ${ }^{17}$

A vida rural era vista pelo arcebispo, não só como o ideal a ser preservado pelas populações já nela inseridas, mas também como alternativa de vida para os desafortunados das cidades. Rumo aos campos! Esse chamamento da Arquidiocese vinha inserido na argumentação que salientava as vantagens da vida rural sobre a urbana. Elogiava-se a vida rural, como um tipo de existência não secularizada, no qual a religião continuava a desempenhar seu papel de construtora de "um mundo comum no âmbito do qual toda a vida social recebe um significado último que obriga a todos". ${ }^{18}$

A supremacia da vida rural sobre a dos grandes centros, nos quais se relevava uma existência onde o magistério católico exercia-se com muito mais dificuldades e onde o controle da Igreja sobre as populações tendia a decrescer, era assim argumentado por D. João Becker:

"Fala-se muito da crise do trabalho e do número crescente dos desempregados. Esta crise se manifesta assim entre nós como em todos os países. Os produtos das fábricas não acham mercados suficientes. Verifica-se uma hiperprodução em conseqüência do grande número de operários (...)

É necessário que as populações rurais não venham às cidades na esperança de conseguirem maior lucro com menos trabalho. Muitas vezes, ouve-se dizer que a vida na cidade é mais agradável, oferece mais diversōes do que a permanência nas colônias e nos campos.

Em vez de continuarem o seu trabalho honesto e remunerador na lavoura, dirigem seus passos às cidades industriais onde, em vez de conforto, encontram miséria, conseqüência muitas vezes do jogo e dos divertimentos demasiados.

Saiba o povo que as ocupações na lavoura são mais saudáveis para o corpo e o espírito do que o serviço constante nos estabelecimentos industriais.

Por isso, os operários das cidades que não tenham suficiente trabalho, deveriam encaminhar-se para os meios de onde com mais facilidade poderiam conseguir os meios de sua subsistência. Rumo aos campos! 
Quem quer trabalhar acha mais facilmente ocupação nas zonas rurais que nas cidades.

()s nossos prezados cooperadores, os revmos., srs. vigários e mais sacerdotes ensinem esta doutrina ao povo, confiados aos scus cuidados espirituais, e podem estar certos de que prestarão um relevante serviço às respectivas famílias e contribuirão poderosamente para a solução da crise do trabalho". ${ }^{14}$

A argumentação do arcehispo não levava em consideração os gravíssimos problemas fundiários revelados pelo RS, ligados à penetraçāo do capitalismo no campo em condiçôes yue "privilegiaram os interesses econômicos e políticos de uma minoria dominante em detrimento de necessidades sociais mais amplas". A luta pela ocupação de terras aptas ao trabalho revela a violência que cercou a saga das populaçôes rurais, no afã de radicarem-se como pequenos proprietários no Estado. ${ }^{21}$

() clogio às excelências da vida rural fazia-se juntamente com a suspeição posta ao aprofundamento da industrialização nos grandes centros. () avanço capitalista era visto como o advento de uma era dominada pela mecanizaçâo, pelo primado da técnica, capaz de acelerar o processo de laicizaçāo $\mathrm{em}$ curso. A moderna tecnologia industrial inaugurava um modo de vida em que cada ve» mais era dificuldade o papel normatizador do catolicismo sobre as populaçôes. Dessa forma, condenava-se sobretudo, o "american way of life", visto como o império da impessoalidade tecnológica, como a negação de uma vida santa, orientada segundo os parâmetros éticos do catolicismo. Em outras palavras, a sociedade norte-americana apresentava-se cada vez. mais distante da unidade moral pregada pela Igreja e perseguida pelo seu ideal de recristianização social.

A tecnologia norte-americana era apreendida como a aliada natural do "bolchevismo" no seu afã de destruir os alicerces da sociedade cristã ocidental. $\mathrm{O}$ avanço tecnológico, indo de encontro aos valores espirituais, era visto como um perigo enorme para o bom andamento da obra de recristianizaçâo social. Daí o louvor às vantagens da vida rural:

"O sistema bolchevista procura a destruição de todo o mundo espiritual e se esforça por realizá-la com um fanatismo sem igual. (O progresso técnico, a mecanização do trabalho, as máquinas, os tratores, a eletrificação, tudo isso the supre as manifestações da vida espiritual. 
()s bolchevistas querem tudo americanizar. A técnica dos Estados Norte-A mericanos é por eles considerada como o meio mais efica/ para conseguir o seu predomínio no mundo. Uma aliança entre a América e o comunismo russo é o fim que eles visam nas suas aspiraçōes. Divinizam a máquina". ${ }^{22}$

A condenação arquidiocesana à fomentaçâo do avanço tecnológico ia de encontro ao que considerava os dois maiores centros irradiadores do moderno espírito anticristāo: os Estados Unidos e a União Soviética.

A política de tratorizaçāo encabeçada por Stalin era percepcionada pelo arcebispo como evidência de um plano visando à superioridade bélica sobre o mundo. Ao mesmo tempo, o esforço soviético em montar uma indústria de base era visto como um indício seguro de sua tentativa de desestabilizar o ocidente através de uma superprodução, fato que teria o objetivo de levar à crise do capitalismo. Por isso a tecnologia industrial, tanto do ocidente como sovićtica, era vista por D. João Becker como um fator de nivelamento dos resultados tanto de uma como de outra parte. Ambas levavam à desagregaçāo da sociedade ocidental. A "concatenação diabólica dos fins do comunismo" era assim entendida pelo arcebispo:

“... industrialização para armar, as mais perfeitas armas de guerra, juntamente com o aumento da produção que, lançada no mercado mundial, como tem acontecido nos últimos anos, determinará o desequilíbrio econômico e o descontentamento geral, o que constitui um terreno propício para a revolução; enfim, a guerra mundial para conseguir o triúnfo da revolução comunista com a destruição total da civilizaçāo cristā". ${ }^{23}$

O periódico da Arquidiocese de Porto Alegre posicionava-se pela superioridade da vida rural, pelas virtudes das populaçōes não "contaminadas" pelo modernismo trazido pela vida atual, pelas seduções do "mau cinema" e das "diversôes levianas". No meio rural, ainda conservavam-se os costumes rígidos que regiam as verdadeiras famílias cristās. Lá não se viam, entronizados nas salas de suas casas "quadros de nú artístico", ou "focinhos sorridentes de artistas de Hollywood", como nas paredes "do lar 'chic' e moderno", 24 dos grandes centros urbanos.

D. João Becker, ao salientar a supremacia da vida rural sobre a urbana, integrava o coro das vozes que, simpatizando claramente com a solução autoritária, há muito que retratavam benignamente o campo. 
Pensadores como Plínio Salgado, Alberto Torres, Oliveira Vianna, Jackson de Figueiredo e Alceu Amoroso Lima, vinham há algum tempo louvando conservadoramente a vida agrária. ${ }^{25}$

Os teóricos do pensamento autoritário brasileiro, aliás, nesse ponto, estavam congruentes com o discurso nazifascista. Tanto o nacionalsocialismo, quanto o fascismo italiano (guardadas as peculiaridades, obviamente) possuíam um discurso extremamente benigno em relação à vida rural e a valorização do homem do campo, embora sua prática política longe estivesse de efetivamente colaborar para a evolução de seu nível de vida. ${ }^{26}$

A Arquidiocese ao relativizar a idéia de progresso capitalista e ao salientar as vantagens da vida rural, inclinava-se pela defesa de uma sociedade na qual a religiāo continuasse a desempenhar uma função normatizadora, não se retraindo à polarização entre o público e o privado, conforme estudou Berger ao enfocar as conseqüências do processo de secularizaçāo:

“... a moderna sociedade industrial produziu um setor 'localizado' no centro que é algo assim como um 'território livre' com relação à religião. A secularização partiu daí para fora na direção das outras áreas da sociedade. Uma conseqüência interessante disso foi uma tendência para a religião 'polarizar-se' entre os setores mais públicos e mais privado da ordem institucional, especificamente entre as instituiçōes do Estado e da família'. ${ }^{27}$

Uma sociedade verdadeiramente cristianizada não poderia admitir que o germe da laicização minasse os seus fundamentos. A obra de "reconquista do Brasil para Cristo" deveria atingir todos os setores da vida, da economia à cultura, passando, obviamente, pelo Estado. Na obra de cristianização não poderia haver "intervalo cultural" entre a secularização da economia que acompanhou o processo de industrialização no moderno capitalismo e a existência de um Estado e de uma família ainda impregnados de símbolos religiosos, tendências identificada por Berger na laicização do mundo contemporâneo. ${ }^{28}$

Uma contra-ofensiva cristianizadora sobre a sociedade brasileira teria que contar com o amplo contingente ainda não inserido no processo de modernização sócio-econômica advindo com o aprofundamento do capitalismo. Em uma sociedade como a brasileira dos anos 30 e 40 ainda, 
obviamente, encontravam-se grandes possibilidades de manterem-se "controles tradicionais", como os da religiāo, sobre amplos contingentes populacionais. Por outro lado, um projeto de afirmação do catolicismo sobre todos os níveis da vida social, da instauração de uma verdadeira unidade moral baseada na ética cristã interpretada pelo magistério católico, esbarraria na dinâmica das transformações aceleradas no Brasil, embora o caso brasileiro estivesse muito longe de uma situação limite como a enfocada por Berger:

"Uma sociedade industrial moderna requer a presença de amplos quadros de pessoal técnico e científico, cujo treinamento e organização social pressupõe um alto grau de racionalização, não só a nível de infra-estrutura mas também a nível de consciência. Qualquer tentativa de reconquista tradicionalista ameaça desmantelar os fundamentos racionais da sociedade moderna". ${ }^{29}$

Era mister que o Brasil não se deixasse contaminar pelo vírus destruidor de valores cristãos, representado pelo triunfo de uma ordem capitalista plenamente configurada. Um processo de modernização econômica rumo a uma sociedade impessoal e laicizada só podia contentar os inimigos da religião católica. Entre esses, somando-se aos figadais opositores franco-maçons e comunistas colocava-se agora o grande capital norte-americano e judeu. Contra essas investidas, só a instauração de uma ordem corporativa, baseada na doutrina social católica teria sucesso, ao impedir o primado da idéia de lucro, alheia a qualquer limite ético.

A Arquidiocese de Porto Alegre ao defender a preservação dos valores tradicionais que orientavam a vida das populaçōes rurais afastava-se das transformações modernizantes em curso no Brasil nas décadas de 30 e 40 . Nesse período há todo um esforço coordenado pelo Estado no sentido de agilizar a queima de etapas rumo a uma economia capitalista. Os planos e instituições criados pelo governo federal a fim de agilizar e modernizar a economia em um sentido capitalista atestam esta tentativa ${ }^{30}$ Esse esforço modernizador ultrapassava o terreno exclusivamente econômico, visando também a:

“... estabelecer novos padrōes e valores, ou reafirmar os padrōes específicos das relaçōes e instituições de tipo capitalista. Note-se que a cultura brasileira ainda estava 
impregnada das heranças dos valores surgidos na sociedade escravocrata. (...) Nesse contexto, a Revolução de 1930 c as inovações nos anos posteriores provocaram a reformulação dos ideais e padrōes de tipo capitalista". ${ }^{31}$

Ora, a moderna sociedade urbana $\mathrm{c}$ industrial era vista por D. Joâo Becker como prescindindo da "moral dos Evangelhos". 32

Assim, os ideais pregados pela Arquidiocese não eram endossados pelas metas visadas pelo programa governamental, no qual justamente objetivava-se dotar o país de uma infra-estrutura e de uma cultura que catalizasse a superação de estruturas pré-capitalistas. Contudo, os esforços do Estado Novo no sentido de harmonizar os interesses entre capital e trabalho através da legislação social eram louvados como evidências do acatamento dos princípio da doutrina social da Igreja por Vargas.

$\mathrm{O}$ aprofundamento do capitalismo, trazendo consigo, justamente a ruptura com valores tradicionais, expondo amplos contingentes populacionais de origem agrária à desagregação de um tipo de vida onde o magistério católico fazia-se com maior facilidade, não podia ser aceito sem reservas. A unidade moral perseguida pela recristianização da sociedade era o único meio de não sucumbir ao comunismo. $O$ crescimento econômico, mesmo que revelando-se momentaneamente, não poderia criar, por sí só, um clima de paz social permanente. Mesmo uma política social justa, capaz de elevar a vida do trabalhador seria ineficaz nesse sentido se prescindisse do papel formador da Igreja.

"Sem dúvida, as leis que têm sido elaboradas pelo governo para auxílio dos trabalhadores, a redução das horas de trabalho, a proibição dos serões, a higiene das minas e das fábricas, a fundação de caixas de socorros, tudo isto é excelente, mas não basta.

Acreditais que um operário, educado fora do cristianismo e talvez odiando-o, imbuído de doutrinas atéias ou materialistas, se dará por satisfeito do que por ele fizerem o Estado ou a caridade? Ele não dirá nunca: 'Basta'! As suas necessidades reais ficarão satisfeitas, admito-o, mas se-lo-ão as suas necessidades fictícias? Assegurai-lhe o pão para ele e para a sua família, e ele vos pedirá os meios para saciar a sede de gozo que o devora, e talvez que o faça em nome da justiça, pois que não tem dela senão noçōes errôneas". ${ }^{33}$ 
A questāo prioritária de qualquer política social radicaria, para a Arquidiocese, no conteúdo que lhe emprestaria a observância do magistério católico. A política social não poderia existir desvinculada de um referencial mais amplo, representado pela doutrina católica. Voltavase sempre, na argumentaçâo da Arquidiocesé, à problemática da procura da almejada unidade moral, capaz de articular os atos governamentais ao ideal de salvação e conservação da Igreja.

Essa busca pela afirmação de uma unidade moral orientada pelo magistério católico trazia consigo, tanto a condenaçäo à modernidade enquanto projeto cult ural alicerçado na oposição abstrata entre o "novo" e a tradição, ${ }^{34}$ quanto ao aprofundamento de transformaçōes socioeconomicas capazes de romper com um passado no qual o catolicismo referenciava-se. Permaneceu o endosso irrestrito à experiência varguista de governo, numa visăo fragmentária, que se atinha às suas similitudes com o projeto católico, sem ater-se à virtual oposição entre a particularização da proposta de neocristandade advogada pela Arquidiocese e as transformaçōes sociais catalizadas pelas metas governamentais.

\section{NOTA}

1. BERMAN, Marshall. Tudo o que é sólido desmancha no ar. São Paulo: Companhia das Letras, 1986. p. 223.

2. BICKKER, D. João. A decadência da civilizaçâo. Porto Alegre: Típografia do Centro, 1940. p. 143.

3. BICKKIR, D. João. A Igreja ('atolica e a pacificação mundial. Porto Alegre: s.ed., 1945. p. 142 .

4. Idem.

5. BI:CKER, D. João. A decadência da civilização. op. cit., p. 191.

6. BECKLiR, D. Joāo. A Igreja Católica e a Pacificaçâo Mundial. op. cit., p. 143.

7. BECKFR, D. João. Sobre o novo I istado brasileiro. In: Unitas. Porto Alegre, v. 20, n. 11, p. $318,1933$.

8. Idem. p. 322.

9. Id., ibid. p. 334 .

10. BECKER, D. João. A Igreja Católica e a Pacificação Mundial. op. cit., p. 60-61.

11. Idem. p. 60.

12. BECKER, D. Joâo. Imperativos da atualidade. op. cit., p. 104-106.

13. Idem. p. 107.

14. Id. ibid. p. 108-109.

15. Partido Católico. Fstrela do Sul, Porto Alegre, 15 maio, 1932. p. 1. (O grifo é nosso.)

16. Partido Católico. Eistrela do Sul, Porto Alegre, 15 de maio, 1932. p. 1. (O grifo é nosso.)

17. Idem. 
18. BERGER, Peter. $O$ dossel sagrado. São Paulo: Paulinas, 1985. p. 145.

19. BECKER, D. João. Cristo e a república. In: Unitas, Porto Alegre, v. 17, n. 1-2, p. 81. 1931.

20. KLIEMANN, Luiza Helena Schmitz. RS: terra e poder. História da questão agrária. Porto Alegre: Mercado Aberto, 1986. p. 152.

21. Idem. p. 145-147.

22. BECKER, D. Joâo. O comunismo russo c a civilizaçăo cristã. op. cit., p. 386.

23. Idem. O laicismo e o estado moderno. In: Unitas, Porto Alegre, v. 18, n. 9-10, p. 534, 1931.

24. Pregando. Estrela do Sul, Porto Alegre, 28 set., 1939. p. 4.

25. VIANNA, Luiz Wernwck. Liberalismo e sindicato no Brasil. Rio de Janeiro: Paz e Terra, s.d. p. 133.

26. POULANTZAS, Nicos. Fascismo e ditadura. São Paulo: Martins Fontes, 1978. p. 304-316.

27. BERGER, Peter. op. cit., p. 142.

28. Id. ibid. p. 141-142.

29. Id. ibid. p. 143-144.

30. IANNI, Octávio. Estado e planejamento econômico no Brasil (1930-1970). Rio de Janeiro: Civilização Brasileira, 1977. p.22.

31. Idem. p. 22-23.

32. BECKER, D. João. A Igreja Católica e a pacificação mundial. op. cit., p. 84.

33. Idem, p. 83-84.

34. HABERMAS, Jurgen. Modernidade versus pós-modernidade. Arte em Revista, n. 7, p.86, 1983. 